\title{
Nonadherence to Drugs among the Hypertensive Patients in Outpatient Department of a Secondary Hospital of Bangladesh
}

\author{
Mohammad Ullah, Suman Kumar Saha, Md. Toufiqur Rahman, Md. Abdul Karim, Rashid Ahmed \\ Department of Cardiology, Col. Malek Medical College, Manikganj
}

Keywords:

Hypertension,

Risk factors,

Drug adherence,

Bangladesh.

\begin{abstract}
:
Background: One fifth Bangladeshi adults are hypertensive. Forty percent of them know that they are hypertensive. 53\% to 75\% hypertensive people have got uncontrolled hypertension. One of the most important causes of uncontrolled hypertension is nonadherence to drugs. We tried to find the causes of non adherence of drugs among the patients with HTN in a secondary care hospital of Bangladesh.
\end{abstract}

Methods: The study was conducted from March 2018 to June 2018. Total 144 patients with HTN were included in the study. Taking drugs in less than $80 \%$ of the days of previous six months was defined as nonadherence. We used Hill Bone compliance scale to find out the causes of nonadherence to drugs.

Results: Out of 144 patients 79 patients (55\%) were non adherent to drugs. $36.8 \%$ patients forget to take their drugs, $34.02 \%$ patients run out of drugs, $29.86 \%$ patients miss taking drugs when they feel better, $15.27 \%$ patients skip their drugs before going to the doctor and $14.58 \%$ patients decide not to take drugs anymore without any specific reason. In most of the patients there are more than one causes of nonadherence. $85.9 \%$ patients with nonadherence had uncontrolled hypertension and $66.6 \%$ of the nonadherent patients had target organ damage. Nonadherence is more in elderly patients and with increased duration of hypertension.

Conclusion: Fifty five percent of the diagnosed hypertensive population is nonadherent to their drugs. We must take measures to diagnose HTN among our population and find the ways to make them adherent to their treatment.

(Cardiovasc. j. 2019; 11(2): 105-113)

\section{Introduction:}

Worldwide, $13.5 \%$ of all premature deaths are attributable to hypertension (HTN). ${ }^{1}$ Elevated blood pressure accounts for two thirds and onehalf of all cases of stroke and ischemic heart disease, respectively. Eighty percent of this burden occurred in low- and middle-income countries. ${ }^{2}$ Treatment of hypertension reduces the risk of stroke by $30-41 \%$ and of coronary heart diseases by $22 \% .{ }^{3}$ For every $20 \mathrm{mmHg}$ systolic or $10 \mathrm{~mm}$ of $\mathrm{Hg}$ diastolic increase in blood pressure, there is a doubling of mortality from both ischaemic heart disease (IHD) and stroke. ${ }^{4}$ Despite knowing these facts, the rate of HTN control in most of the countries is $<50 \% .{ }^{5-8}$ One of the most important causes of uncontrolled HTN is non-adherence to drug. ${ }^{9}$ Fifty to seventy percent of the hypertensive patients in
Bangladesh has got uncontrolled HTN and one of the important causes of it was low adherence to drugs. It is also an established fact in other populations. ${ }^{9,10}$

Non-adherence occurs when a patient does not: initiate a new prescription, implement as prescribed, or persist with treatment. Non adherence to drugs in is a worldwide problem. Lack of medication adherence is estimated to cost European governments $\cdot 125$ billion per year; and cost arising due to complications of poor adherence represents $14 \%$ of total healthcare expenditure in the United Kingdom's National Health Service. ${ }^{11}$ It sets a continuous cycle, with poor medication adherence leading to poor health outcomes, increased service utilization and health care costs, which are passed on to the

Address of Correspondence- Dr. Mohammad Ullah, Department of Cardiology, Col. Malek Medical College, Manikganj, Bangladesh. Email-firoze1970@gmail.com

(C) 2018 authors; licensed and published by International Society of Cardiovascular Ultrasound, Bangladesh Chapter and Bangladesh Society of Geriatric Cardiology. This is an Open Access article distributed under the terms of the CC BY NC 4.0 (https:// creativecommons.org/licenses/by-nc/4.0). 
patient and then lead to further effects on adherence. ${ }^{12}$ About $8 \%$ of the global total health expenditure, could be avoided from adherence to medicine. ${ }^{13}$ Low adherence to medication also reduces the work productivity of the hypertensive patients. ${ }^{14}$ Low adherence is the most common cause of apparent resistant hypertension. ${ }^{15}$ Poor adherence to antihypertensive therapy is associated with increased risks of coronary and cerebrovascular events. ${ }^{16}$ It increases the probability of myocardial infarction and stroke by two times and that of heart failure by three times. ${ }^{17}$

Identification of the problem is crucial as the prevention strategy depends on the type of pattern. In a systemic review involving the studies in developing countries, it was concluded that low household income and socioeconomic status; knowledge and beliefs of hypertension and its management; avoiding side effects of medications; cost of medication; use of herbal preparations; absence of symptoms; irregular follow-up; and dissatisfaction with the treatment and health services provided. ${ }^{18}$

A study of the Prevalence, Awareness, Treatment and Control of Hypertension among Elderly in Bangladesh and India found that $45 \%$ of elderly people in these two countries suffer from hypertension, $40 \%$ of the patients are aware of their disease diagnosis and $10 \%$ of them are adhering to treatment. ${ }^{19} \mathrm{~A}$ number of studies were conducted in different regions of Bangladesh in different institutions and field levels. ${ }^{20-22}$ Some of the studies were done among the self declared hypertensive patients (previously declared hypertensive by unqualified doctors or qualified doctors). ${ }^{20,22}$ They have got different results regarding the level of adherence to anti hypertensive treatments.

\section{Methods-}

This cross sectional study was conducted from March 2018 to June 2018 in Outpatient Department of Cardiology, Manikganj Sadar Hospital. Manikganj is a district $60 \mathrm{~km}$ from Dhaka. She has got a total population of 1.4 million, with 869,000 people more than 18 years of age and a literacy rate of $56 \%$. Patients mostly of low and lower middle socioeconomic class attend the outpatient department of Sadar Hospital. Patients who were already diagnosed as hypertensive and were taking anti hypertensive drugs were included in the study. Total 144 patients were included in the study. Compliance with drug treatment was mainly assessed in the study. Patients who were taking drugs on more than $80 \%$ of the days in previous six months were considered as compliant. Modified Hill Bone compliance scale (346 guideline) was used to assess the causes of nonadherence to drugs. ${ }^{23}$ Nine factors of original compliance were included in the study. These are as follows-

A. Forget to take your high BP medicine?

B. Decide NOT to take your high BP medicine?

C. Forget to get prescriptions filled?

D. Run out of high BP pills?

E. Skip your high BP medicine before you go to the doctor?

F. Miss taking your high BP pills when you feel better?

G. Miss taking your high BP pills when you feel sick?

H. Take someone else's high BP pills?

I. Miss taking your high BP pills when you are careless?

\section{Results:}

This is a cross sectional observational study conducted in a secondary level hospital, a district hospital, about sixty kilometers from the capital city of Bangladesh. A total 144 patients were included in the study. Minimum age of the patients was 20 years and maximum age 90 years with an average age of 56.1 years. Most of the patients $(64.6 \%)$ were in the age group of 50-69 years. Sixty six of the patients were male and 78 were female. Maximum duration of HTN was 30 years and average duration was 66.5 months. One hundred and three (71.5\%) patients had their blood pressure not controlled at the time attending the OPD. Among them, 103 patients had systolic blood pressure $\geq 140 \mathrm{~mm}$ of $\mathrm{Hg}, 99$ patients had diastolic blood pressure e" $90 \mathrm{~mm}$ of $\mathrm{Hg}$ and 92 patients had both systolic and diastolic pressure raised. Average systolic blood 
pressure of the patients was $145.1 \mathrm{~mm}$ of $\mathrm{Hg}$ and average diastolic blood pressure was 90.7 $\mathrm{mm}$ of $\mathrm{Hg}$.

\section{Table-I}

Distribution of total patients and patients with nonadherence according to age $(N=144)$.

\begin{tabular}{lcc}
\hline Age group & Total & Nonadherence \\
\hline $20-29$ & 3 & $1(33.3 \%)$ \\
$30-39$ & 7 & $2(28.7 \%)$ \\
$40-49$ & 19 & $10(52.6 \%)$ \\
$50-59$ & 44 & $24(54.5 \%)$ \\
$60-69$ & 49 & $26(53.1 \%)$ \\
$70-79$ & 17 & $12(70.6 \%)$ \\
$>80$ & 5 & $3(60 \%)$ \\
& 144 & $78(54.2 \%)$ \\
\hline
\end{tabular}

Seventy eight patients out of 144 (54.2\%) were nonadherent to their anti hypertensive drugs. Nonadherence rate was highest in the age group of 70 to 79 years, which is $70.6 \%$. In the age groups 40-69 years the nonadherence was $52.6 \%-54.5 \%$. The adherence rate was better (about $70 \%$ ) in younger patients (20-39 years group), though the number of patients was less in this groups. Out of 78 female patients 40 (51.28\%) were nonadherent and out of 66 male patients 38 $(57.57 \%)$ were nonadherent $(\mathrm{p}>0.05)$. Nonadherence rate increased with the duration of HTN. In patients with HTN duration less than one year nonadherence rate was $7.1 \%$. In patients with duration of HTN 1-5 years, nonadherence rate was $60.8 \%$ and with duration of HTN more than 5 year, nonadherence rate was $69.2 \%$.

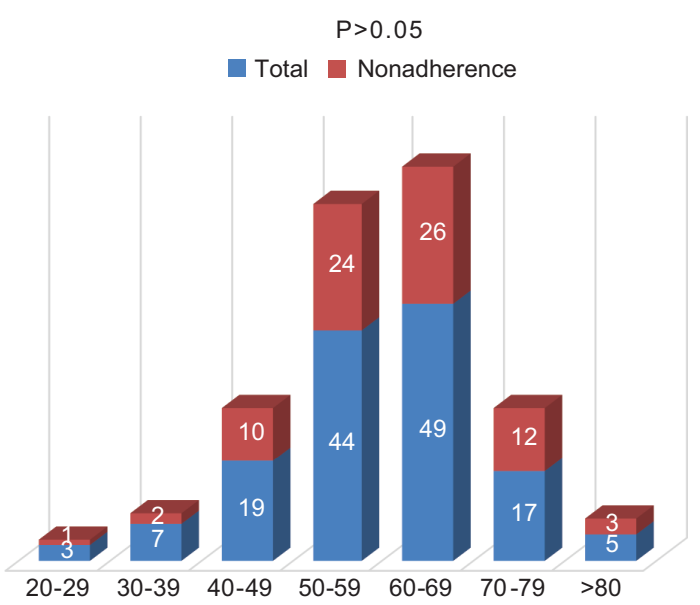

Fig.-1: Ratio of total patient and non adherent patients in different age groups.

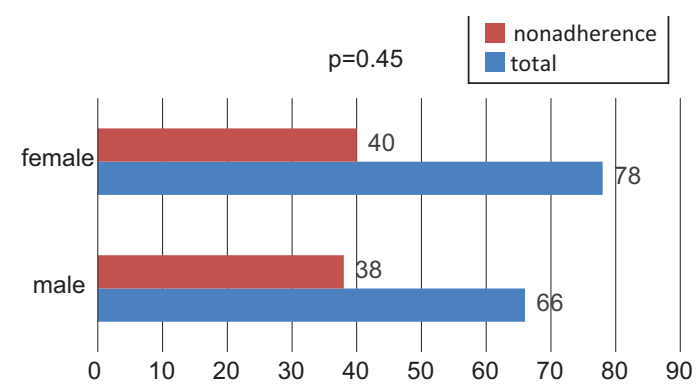

Fig.-2: Distribution of total and nonadherent patients according to gender.

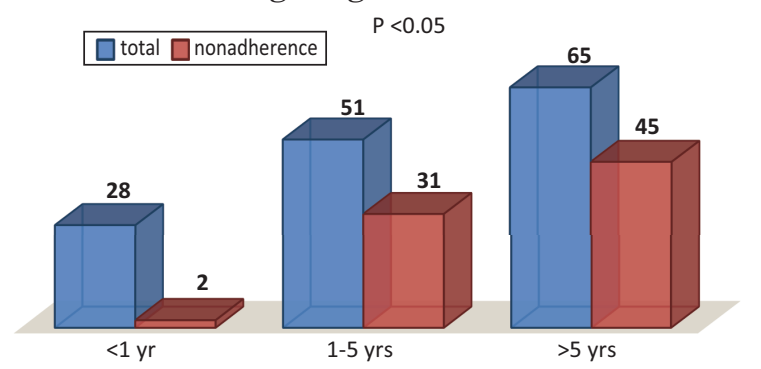

Fig.-3: Distribution of total patients and nonadherent patients according to duration of hypertension.

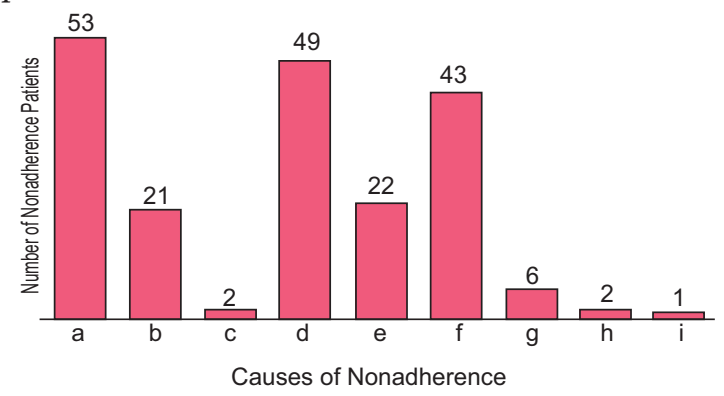

Fig.-4: Distribution study population according to causes of nonadherence (some of the patients had more than one causes).

a. Forget to take your high BP medicine? b. Decide NOT to take your high BP medicine? c. Forget to get prescriptions filled? d. Run out of high BP pills? e. Skip your high BP medicine before you go to the doctor? f. Miss taking your high BP pills when you feel better? f. Miss taking your high BP pills when you feel sick? h. Take someone else's high BP pills? i. Miss taking your high BP pills when you are careless?

Regarding the causes of non adherence, 53 (36.8\%) patients forget to take their drugs, 49 $(34.02 \%)$ patients ran out of their anti hypertensive drugs, 43 (29.86\%) patients stopped taking drugs when they feel better, 22 (15.27\%) patients stopped taking drugs before visiting the doctor, 21 (14.58\%) patients decided not to take the drugs anymore without any specific reason, $6(4.16 \%)$ patients stopped taking drugs when 
they become sick for any other reason, 2 (1.38\%) patients lost their prescriptions and failed to collect the drugs from pharmacy, 2 (1.38\%) patients took other person's anti hypertensive drugs when they ran out of their own drugs, one (0.69\%) patient admitted that he stopped taking drugs because he was careless. The cause of nonadherence was more than one in most of the

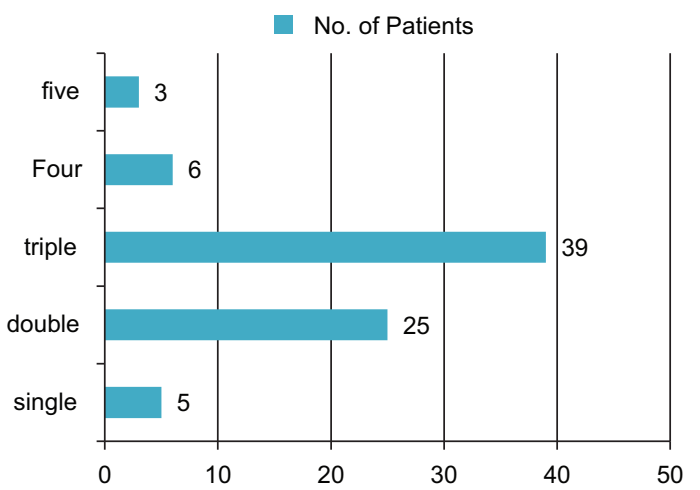

Fig.-5: Distribution of study population according to number of causes for nonadherence.

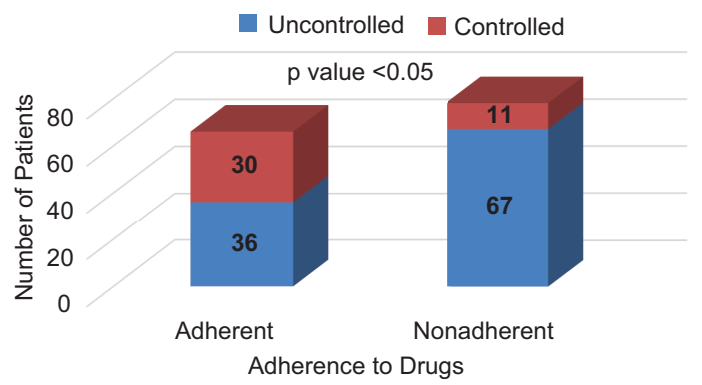

Fig.-6: Ratio of uncontrolled HTN according adherence to drugs.

patients. In $39(27.08 \%)$ patients it was three causes and $25(17.36 \%)$ patients had two different causes of nonadherence.

One hundred and three patients comprising $71.2 \%$ of the study patients had uncontrolled HTN. Among the patients who were adherent to drugs, $54.5 \%$ had uncontrolled HTN when they reported to the OPD. On the other hand, patients who were nonadherent to drugs $85.9 \%$ had uncontrolled HTN at the time of reporting to OPD.

\section{Table-II}

Distribution of Target organ damage in study population in relation to drug adherence

$$
(N=144) \text {. }
$$

\begin{tabular}{lccc}
\hline & TOD & No TOD & p-value \\
\hline Non adherent (78) & 52 & 26 & $<0.05$ \\
Adherent (66) & 24 & 42 & \\
\hline
\end{tabular}

TOD- Target organ damage.
Among the 78 patients who were nonadherent to anti hypertensive drugs $66.6 \%$ had target organ damage. On the other hand, among the 66 patients who were adherent to drugs $36.3 \%$ patients had target organ damage. This difference in the rate of target organ damage was statistically significant.

Of the 144 patients, 54 patients were getting single drug and 90 patients were getting more than one drugs. Out of 54 patients, 25 patients were getting angiotensin receptor blocker (ARB), 22 patients were getting beta blockers, and seven patients were getting calcium channel blockers. Out of 90 patients who were using more than one drug, 53 patients were getting two drugs, 31 patients were getting three drugs and 6 patients were getting four dnrugs. $50 \%$ of the single drug user were nonadherent to drug and $63 \%$ of multiple drug users were nonadherent $(p=0.12)$. there was no significant difference regarding the prevalence of nonadherence in relation to number of drugs $(p=0.47)$.

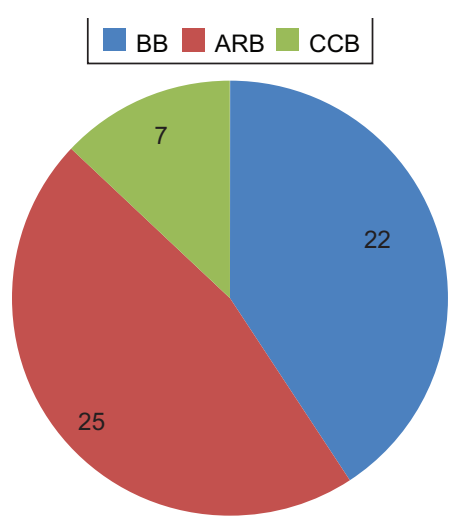

Fig.-7: Distribution of drugs among the patients using single antihypertensive drug $(n=54)$.

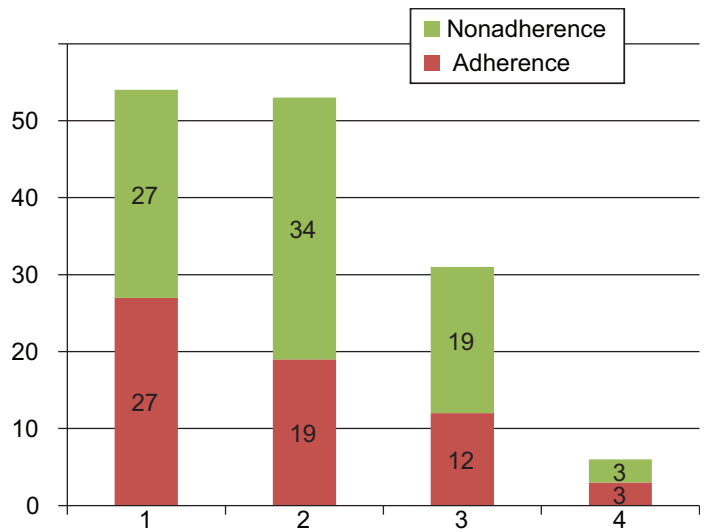

Fig.-8: Prevalence of drug nonadherence according to number of drug used $(N=144)$. 
Table-III

Number of drugs in relation to nonadherence in study population $(N=144)$.

\begin{tabular}{lcccc}
\hline No. of Drugs & Total & Drug adherence & Drug nonadherence & p value \\
\hline 01 & 54 & $27(50 \%)$ & $27(50 \%)$ & $0.47^{\text {NS }}$ \\
02 & 53 & $19(35.8 \%)$ & $34(64 \%)$ & \\
03 & 31 & $12(38.7 \%)$ & $19(61.3 \%)$ & \\
04 & 06 & $03(50 \%)$ & $03(50 \%)$ & \\
\hline
\end{tabular}

NS- Not significant.

\section{Discussion:}

Adherence with a treatment plan includes the followings - a) adherence with the nonpharmacological measures and lifestyle modifications, b) adherence with the drug treatment, c) adherence with the follow up schedule for treatment and sometimes d) adherence with the further or advanced management of the diseases. In this study we considered the adherence with drug treatment only. We tried to measure the compliance by asking the patient's history and taking drugs more than $80 \%$ of the days in last six months was defined as compliance. This method of estimation may underestimate the level of noncompliance. But other means of measuring compliance can be costly and include measuring plasma drug levels or using electronic equipment to ascertain the number of times that drug containers have been opened in a given period of time. Most of these measures are impractical for usual clinical practice or for large, community-based studies.

We modified Hill Bone compliance scale for evaluation of adherence level. This scale is verified by different studies and suggested by the guidelines. ${ }^{24}$ This is applicable in the community with limited literacy. Drug compliance behavior can be assessed in a short period of time. It helps to detect the faults at the level of patient as well as at the level health care system and pharmaceuticals also. And it has got different regional versions like African, Persian, Malaysian, and Korean. ${ }^{25-28}$ But there is no Bangladeshi or Indian version.

$54.2 \%$ of the study population was nonadherent to antihypertensive drugs in our study. In the study conducted in the community level in different places in Chittagong division of Bangladesh by Khanam et al. in 2009 showed that non-adherence was only $26 \% .{ }^{20}$ In a study conducted in Rajshahi Medical College in 2011, it was found that non-adherence rate to anti hypertensive medication was $85 \%$. Lack of knowledge about the disease, it's consequence, it's medication and lack of availability of healthcare facilities and medications were the reasons responsible for non-adherence. ${ }^{21}$ Another study in Comilla (Medical college based) in 2016 has also revealed only $35 \%$ adherence to drugs among the hypertensive patients. ${ }^{29}$ Different populations with different socioeconomic, cultural and educational background may be the reason of such variations.

This rate of nonadherence to anti hypertensive drugs is also similar to the reports other developing countries in Asia and Africa. In a hospital based study in Nepal $51.9 \%$ of the patients were adherent to anti hypertensive treatment. Female patients and married persons were more compliant. Availability of drugs and duration of HTN was also important factors. ${ }^{30}$

Ina study conducted in Karachi in the indoor department the nonadherence rate was $68.1 \% .{ }^{31}$ In a study in Tehran, the adherence to anti hypertensive drugs was only $24 \%$. Unhealthy lifestyle like smoking, salt intake \& lack of physical exercise and lack of perception about the ominous nature of HTN and polypharmacy were responsible for the non-adherence. ${ }^{32}$ Drug nonadherence was found in $66.7 \%$ in a study in Ghana and Nigeria. ${ }^{33}$

It was different in Kuwait. In a study conducted in Kuwait, it was showed that adherence rate was $88.6 \%$. Adherence to antihypertensive medications is also poor in Australia, with up to 
half of all treated hypertensive patients discontinuing treatment by 12 months. ${ }^{5}$

In our study there was no gender variation regarding the adherence level. But Khanom et al. found that men in comparison to women are less likely to be adherent. ${ }^{20}$ The effect of gender is also different in other studies. ${ }^{21,34}$ The proportion of female patients in our study was higher than those studies. The timeline and socioeconomic condition are also different. This may be the reason for their difference regarding adherence level.

In our study elderly patient were more nonadherent to drugs, which are not supported by the study of Kahnom et al. They found that older patients and patients with higher socioeconomic condition and higher education are less likely to be non-adherent. Increasing age and awareness of complication of hypertension were responsible for better adherence in Vietnam. ${ }^{14,35}$ One of the reasons of difference may be the socioeconomic condition of our population. Most of the patients of our study are from low socioeconomic condition. As the OPD of the secondary level pubic hospital is being used by people low socioeconomic condition, as the treatment cost is very low and they get most of the drugs free of charge from the hospital. Our study also contradicts with their findings, as they mentioned, when care is provided by a qualified doctor and when HTN is associated with comorbid conditions, the adherence rate is higher. In our most of the patients are prescribed by the qualified doctors of the OPD of hospital, even then the nonadherence rate is higher. ${ }^{20}$

Marital status is also an important factor in some studies. It two studies conducted in Nepal and Bangladesh, married persons are more likely to adherent to drugs. ${ }^{21,30}$ But a study in Karachi revealed no relation between marital status and adherence rate. ${ }^{31}$ But we haven't studied the impact marital status on drug adherence.

Most common cause of nonadherence in our study population was forgetfulness to take the drug (38\%). In $34 \%$ cases they run out of drugs and in $30 \%$ cases they stop taking drugs when they feel better. This unintentional patient behavioral factor, forgetfulness, is an important cause of drug nonadherence in different studies. ${ }^{36,37}$ Being forgetful and not having any symptoms, is one of the most common reasons for missing the medications in other geographical areas. ${ }^{37,38}$ In Nigeria, most of the patients (90.1\%) sometimes forget to take their medications or do not bring their medications along when they leave home (94.3\%). ${ }^{39}$

Running out of drug is the second most important cause of nonadherence in our study population. Most of these antihypertensive drugs are expensive, and if patients from low socioeconomic condition fail to collect it free of cost from the hospital. Another important cause of nonadherence was stopping drug when the patient feels better. As most of the hypertensive patients are asymptomatic, proper education is necessary to make the patients understand the long term side effects of uncontrolled HTN even when it is asymptomatic. Suggestion by unqualified doctors (village doctors) in Bangladesh is also an important cause of stopping taking drugs. ${ }^{29}$ Use of herbal medicine is also an important cause of nonadherence among the patients in developing countries, ${ }^{18}$ though we haven't studied the use of herbal medicine in our patient population.

In our study $37 \%$ patients were getting single antihypertensive drug. The prevalence of nonadherence was higher ( $63 \%$ vs. $50 \%$ ), but it was not statistically significant. The prevalence of nonadherence was not significantly related to the number of drug used, though there was increased prevalence of nonadherence among the patients who were using more than one drug.

In some studies there was relation of drug with the level of adherence. In a study it was claimed that it was better with ACEi/ARB (50\%) than CCB (<40\%). ${ }^{40-42}$ Another study in Alabama, USA, among patients taking only a single class of antihypertensive throughout the fiscal year, $67.4 \%$ of patients were considered adherent and $70.1 \%$ had controlled BP. Single-class adherence was highest for ARBs (75.6\%) and lowest for BBs $(64.7 \%){ }^{43}$ In a study in Comilla, Bangladesh, has also revealed that single drug regimen and cheaper drugs ensure better compliance. Polypharmacy was responsible for 
non-adherence. ${ }^{31,44}$

The reason behind the discrepancy between our study and other studies may be use of more fixed dose combination drugs in our study. So even the patients were using multiple antihypertensive drugs, they were taking one or two pills.

One of the reasons of high nonadherence of anti hypertensive drugs in our study population may be the consultation hour of the hospital. The consultation hour of the hospital is 8.00 am to $2.30 \mathrm{pm}$. This is the time when most of the patients or their attendants are busy with their daily works. Long waiting time because of huge patient burden in the OPD may also be one of the reasons. It has got two impacts, i) patients don't want to wait for that long time and they don't visit the hospital frequently for consultation and for collection of drugs, ii) doctors get less time for patients education, regarding the importance of taking drugs, lifestyle modification and adverse effects of uncontrolled HTN. In a study in Karnataka, India, health care accessibility, waiting time for consultation and frequent change in medication were identified as probable causes for nonadherence. $^{38}$

The control of HTN was also very poor in our study population (29\%). Eighty five percent of patients with drug nonadherence had uncontrolled HTN and $54 \%$ of the patients with drug adherence had uncontrolled HTN. So optimization of pharamacological and nonpharmacological treatments along with improvement in their compliance level is necessary to improve the control of HTN.

Two thirds of the patients with drug nonadherence had target organ damage. On the other hand two thirds of the patients with drug adherence had no target organ damage. In a study conducted in Rajshahi, half of the patients with drug nonadherence had target organ damage. ${ }^{21}$ The difference may be due to the method of definition and estimation of target organ damage.

\section{Recommendations}

There is no single intervention which will improve the drug adherence among hypertensive patients in all the communities. It should be individualized in every community. We are suggesting some interventions for better adherence in our population. It should be evaluated by community level studies.

1. Motivation of the patients- In most of the cases, patients are concerned about the sideeffects and long-term adverse effects, dependence, disruption to daily lives, asymptomatic nature of the diseased, availability of drugs and financial aspects. Drug adherence can be increased by increasing the patient's perception about the necessity of drugs. At the same time concern about the side effects should be assured.

2. Therapeutic simplification- reduce pill burden, reduce dose frequency. Fixed drug combinations can improve the condition.

3. Availability of drugs- by making it cheaper, which is often difficult. In public hospital, where drugs are available at a low cost or free of cost, should extend their drug dispensing hour so that patients can collect their drugs after their working hours.

4. Patients' awareness that their adherence patterns can change their behavior.

5. Higher proportion of patients who received their prescribed medication in reminder packaging remained on treatment and was less likely to discontinue therapy compared with the non-reminder packaging group. So pharmaceutical industries should change their packaging strategy.

\section{Conclusion:}

Fifty five percent hypertension patients are nonadherent to their anti-hypertensive drugs. Durattion of HTN more than five years is a risk factor for non-adherence. Age and sex are not determining factors. Most of the patient has got multiple causes of non-adherence. Non-adherent patients has got more uncontrolled HTN and target organ damage.

\section{Conflict of Interest - None.}

\section{References:}

1. Lawes CM, Vander Hoorn S, Rodgers A. Global burden of blood-pressure-related disease, 2001. Lancet 2008; 371: 1513 -1518. doi.org/10.1016/S0140-6736(08)60655-8 
2. Lawes CM, Vander Hoorn S, Law MR, Elliott P, MacMahon $\mathrm{S}$, Rodgers A. Blood pressure and the global burden of disease 2000. Part II: estimates of attributable burden. J Hypertens 2006; 24: 423-430. doi:10.1097/01.hjh.0000209973.67746.f0

3. Law MR, Morris JK, Wald NJ. Use of blood pressure lowering drugs in the prevention of cardiovascular disease: meta-analysis of 147 randomised trials in the context of expectations from prospective epidemiological studies. BMJ 2009; 338: b1665. doi.org/10.1136/bmj.b1665

4. Lewington S, Clarke R, Qizilbash N, Peto R, Collins R; Prospective Studies Collaboration. Age-specific relevance of usual blood pressure to vascular mortality: a meta-analysis of individual data for one million adults in 61 prospective studies. Lancet 2002; 360: 1903-1913. doi.org/10.1016/S01406736(02)11911-8

5. Scheltens T, Bots ML, Numans ME, Grobbee DE, Hoes AW. Awareness, treatment and control of hypertension: the 'rule of halves' in an era of risk-based treatment of hypertension. J Hum Hypertens 2007; 21: 99 -106. doi: 10.1038/sj.jhh.1002123

6. Wu Y, Huxley R, Li L, Anna V, Xie G, Yao C, et al. Prevalence, awareness, treatment, and control of hypertension in China: data from the China National Nutrition and Health Survey 2002. Circulation 2008; 118: 2679 - 2686. doi: 10.1161/CIRCULATIONAHA.108.788166

7. Ong KL, Cheung BM, Man YB, Lau CP, Lam KS. Prevalence, awareness, treatment, and control of hypertension among United States adults 1999 - 2004. Hypertension 2007; 49: 69 -75. doi: 10.1161/01. HYP. 0000252676.46043 .18

8. Sulbaran T, Silva E, Calmon G, Vegas A. Epidemiologic aspects of arterial hypertension in Maracaibo, Venezuela. J Hum Hypertens 2000; 14(Suppl 1): S6 -9.

9. Jafar TH, Gandhi M, Jehan I, Naheed A, de Silva HA, Shahab H, et al. Determinants of Uncontrolled Hypertension in Rural Communities in South AsiaBangladesh, Pakistan, and Sri Lanka. American Journal of Hypertension 2008, 31(11): 1205-1214. doi:10.1093/ajh/ hpy071

10. Ullah M, Saha SK. Modifiable Cardiovascular Risk Factors in Hypertensive Patients. Cardiovasc j 2018; 11(1): 10-16. doi.org/10.3329/cardio.v11i1.38236

11. Vrijens B, Antoniou S, Burnier M, de la Sierra A, Volpe M. Current Situation of Medication Adherence in Hypertension. Front Pharmacol 2017; 8: 100. doi: 10.3389/fphar. 2017.00100

12. Luga AO, McGuire MJ. Adherence and health care costs. Risk Manag. Health c. Policy 2014; 7: 35-44. doi: 10.2147/ RMHP.S19801

13. The benefits of responsible use of medicines - Setting policies for better and cost-effective healthcare. Ministers Summit3 October 2012, Amsterdam, The Netherlands. 2012. Available at: http://www.imshealth.com/en/thoughtleadership/ims-institute/reports/responsible-useofmedicines- report\#ims-form
14. Wagner S, Lau H, Frech-Tamas F, Gupta S. Impact of Medication Adherence on Work Productivity in Hypertension. Am J Pharm Benefits 2012; 4(4):e88-e96.

15. Jung O, Gechter JL, Wunder C, Paulke A, Bartel C, Geiger $\mathrm{H}$, et al. Resistant hypertension? Assessment of adherence by toxicological urine analysis. J Hypertens 2013; 31: 766774. ‘doi: 10.1097/HJH.0b013e32835e2286

16. Corrao G, Parodi A, Nicotra F, Zambon A, Merlino L, Cesana $\mathrm{G}$, et al. Better compliance to antihypertensive medications reduces cardiovascular risk. J Hypertens 2011; 29: 610-618. doi: 10.1097/HJH.0b013e 328342ca97

17. Böhm M, Schumacher H, Laufs U, et al. Effects of nonpersistence with medication on outcomes in high-risk patients with cardiovascular disease. The American Heart Journal 2013; 166(2):306-314. doi:10.1016/j.ahj.2013.04.016.

18. Dhar L, Dantas J, Ali M. A Systematic Review of Factors Influencing Medication Adherence to Hypertension Treatment in Developing Countries. Open Journal of Epidemiology 2017; 7: 211-250. doi.org/10.4236/ ojepi.2017.73018

19. Hypertension Study Group V. Prevalence, awareness, treatment and control of hypertension among the elderly in Bangladesh and India: a multicentre study. Bull WHO 2001; 79(6): 490-500.

20. Khanam MA, Lindeboom W, Perez TL, Koehlmoos, Alam DS, Niessen L, et al. Hypertension: adherence to treatment in rural Bangladesh - findings from a population-based study. Glob Health Action 2014, 7: 25028. doi.org/10.3402/ gha.v7.25028

21. Hussain SM, Boonshuyar C, Ekram ARMS. Non-Adherence to Antihypertensive Treatment in Essential Hypertensive Patients in Rajshahi, Bangladesh. AKMMC J 2011; 2(1): 09-14.

22. Alam DS, Chowdhury MAH, Siddiquee AT, Ahmed S, Niessen LW. Awareness and control of hypertension in Bangladesh: follow-up of a hypertensive cohort. BMJ Open 2014; 4: e004983. doi:10.1136/bmjopen-2014-004983

23. Kim MT, Hill MN, Bone LR, et al. Development and testing of the Hill-Bone Compliance to High Blood Pressure Therapy Scale. Prog Cardiovasc Nurs 2000; 15:90-96. doi.org/ 10.1111/j.1751-7117.2000.tb00211.x

24. Whelton PK, Carey RM, Aronow WS, Casey DE Jr, Collins KJ, Dennison Himmelfarb C, et al. 2017 ACC/AHA/AAPA/ ABC/ACPM/AGS/APhA/ASH/ASPC/NMA/PCNA guideline for the prevention, detection, evaluation, and management of high blood pressure in adults: a report of the American College of Cardiology/American Heart Association Task Force on Clinical Practice Guidelines. J Am Coll Cardiol 2018; 71 (19): e127-e248. doi: 10.1016/j.jacc.2017.11.006

25. Lambert EV, Steyn K, Stender S, Everage N, Fourie JM, Hill M. Cross-cultural validation of the Hill-Bone compliance to high blood pressure therapy scale in a south African, primary healthcare setting. Ethn Dis 2006; 16: 286- 291.

26. Dehghan M, Nayeri ND, Iranmanesh S. Validating the Persian Version of the Hill-Bone's Scale of "Compliance to 
High Blood Pressure Therapy". BJMMR 2015; 5(2): 235246. doi:10.9734/BJMMR/2015/13061

27. Cheong AT, Tong SF, Sazlina SG. Validity and reliability of the Malay version of the Hill-Bone compliance to high blood pressure therapy scale for use in primary healthcare settings in Malaysia: A cross-sectional study. Malays Fam Physician 2015; 10(2):36-44.

28. Song Y, Han H, Song H, Nam S, Nguyen T, Kim MT. Psychometric Evaluation of Hill-Bone Medication Adherence Subscale. Asian Nursing Research 2011; 5: 183-188, doi:10.1016/j.anr.2011.09.007

29. Saibal AA, Ahmed MU, Begum SA, Haque A, Uddin S, Islam Z. Compliance to Antihypertensive Drugs among Hypertensive Patients in Eastern Medical College Hospital, Comilla, Bangladesh. EMCJ. Jan 2016; 1(1): 1-5.

30. Bhavana S, Zannatul F, Rabbi F, Ahmed H. Adherence to Medications among Nepali Hypertensive Population: A Hospital-Based Cross-Sectional Study. Biomed J Sci \& Tech Res 2018; 3(5): 1-5. doi: 10.26717/BJSTR.2018.03.000964

31. Bilal A, Riaz M, Shafiq N, Ahmed M, Sheikh S, Rasheed S. Non-compliance to anti-hypertensive medication and its associated factors among hypertensives. J Ayub Med Coll Abbottabad 2015; 27(1):158-163.

32. Kamran A, Sadeghieh Ahari S, Biria M, Malepour A, Heydari H. Determinants of patient's adherence to hypertension medications: Application of health belief model among rural patients. Ann Med Health Sci Res 2014; 4(6): 922-927. doi: 10.4103/2141-9248.144914

33. Boima V, Ademola AD, Odusola AO, Agyekum F, Nwafor $\mathrm{CE}$, Cole H, et al. Factors Associated with Medication Nonadherence among Hypertensives in Ghana and Nigeria. International Journal of Hypertension 2015; 1-8. doi.org/ $10.1155 / 2015 / 205716$

34. Park JH, Shin Y, Lee SY, Lee SI. Antihypertensive drug medication adherence and its affecting factors in South Korea. Int J Cardiol 2008; 128: 392- 398. doi.org/10.1016/ j.ijcard.2007.04.114

35. Nguyen T-P-L, Schuiling-Veninga CCM, Nguyen TBY, Vu T-H, Wright EP, Postma MJ. Adherence to hypertension medication:Quantitative and qualitative investigations in a rural Northern Vietnamese community. PLoS ONE 2017; 12(2):e0171203. doi:10.1371/journal.pone.0171203
36. Griva K, Davenport A, Harrison M, Newman S. Nonadherence to Immunosuppressive Medications in Kidney Transplantation: Intent Vs. Forgetfulness and Clinical Markers of Medication Intake. Annals of Behavioral Medicine 2012; 44(1): 85-93. doi:10.1007/s12160-012-93599364.

37. Al-Mehza AM, Al-Muhailije FA, Khalfan MM, Al-Yahya AA. Drug Compliance Among Hypertensive Patients; an Area Based Study. Eur J Gen Med 2009; 6(1):6-10. doi.org/ 10.29333/ejgm/82628

38. Mallya SD, Kumar A, Kamath A, Shetty A, Reddy T SK, Mishra S. Assessment of treatment adherence among hypertensive patients in a coastal area of Karnataka, India. Int J Community Med Public Health 2016 Aug; 3(8): 19982003. doi.org/10.18203/2394-6040.ijcmph20162185

39. Ezeala-Adikaibe BA, Mbadiwe N, Okudo G, Nwosu N, Nwobodo N. Factors Associated with Medication Adherence among hypertensive Patients in a Tertiary Health Center: A Cross-Sectional Study. Arch Community Med Public Health 2017; 3(1): 024-031. doi.org/10.17352/24555479.000021

40. Simons LA, Ortiz M, Calcino G. Persistence with antihypertensive medication: Australiawide experience, 2004-2006. Med J Aust 2008; 188: 224-227.

41. Conlin PR, Gerth WC, Fox J, Roehm JB, Boccuzzi SJ. Fouryear persistence patterns among patients initiating therapy with the angiotensin II receptor antagonist losartan versus other antihypertensive drug classes. Clin Ther 2001; 23(12): 1999-2010. doi.org/10.1016/S0149-2918(01)80152-1

42. Patel BV, Remigio-Baker RA, Mehta D, Thiebaud P, FrechTamas F, Preblick R. Effects of initial antihypertensive drug class on patient persistence and compliance in a usualcare setting in the United States. J Clin Hypertens 2007; 9(9): 692-700. doi.org/10.1111/j.1524-6175.2007.07194.x

43. Piercefield EW, Howard ME, Robinson MH, Kirk CE, Ragan AP, Reese SD. Antihypertensive medication adherence and blood pressure control among central Alabama veterans. $J$ Clin Hypertens 2017;19: 543-549. doi: 10.1111/jch.12953

44. Kabira M, Iliyasu Z, Abubakara IS, Jibril M. Compliance to medication among hypertensive patients in Murtala Mohammed Specialist Hospital, Kano, Nigeria. Journal of Community Medicine \& Primary Health Care 2004;16(1):1620. doi.org/10.4314/jcmphc.v16i1.32401 